\title{
Reciclagem secundária de rejeitos de porcelanas elétricas em estruturas de concreto: determinação do desempenho sob envelhecimento acelerado
}

\author{
(Secondary recycling of electrical insulator porcelain waste \\ in Portland concrete structures: determination of the \\ performance under accelerated aging)
}

\author{
K. F. Portella ${ }^{1}$, A. Joukoski ${ }^{1}$, R. Franck ${ }^{1}$, R. Derksen ${ }^{2}$ \\ ${ }^{1}$ Instituto de Tecnologia para o Desenvolvimento - LACTEC \\ Centro Politécnico da UFPR, Jd. das Américas, Curitiba, PR 81531-990 \\ ${ }^{2}$ Companhia Paranaense de Energia - Distribuição (COPEL-DIS) \\ portella@lactec.org.br
}

\begin{abstract}
Resumo
O uso de entulhos, entre outros rejeitos industriais e domésticos, pela construção civil vem sendo prática comum em diversos países desenvolvidos, em razão tanto do aumento da quantidade de rejeitos e conseqüente esgotamento de espaços apropriados para seu destino final, quanto da constante e cada vez mais rigorosa fiscalização e punição pelos organismos ambientais competentes. Antecipando maneiras para solução desses problemas, propôs-se o estudo da reciclagem e imobilização de rejeitos de porcelanas elétricas em concreto, em substituição parcial aos agregados graúdos e miúdos naturais. A vantagem não foi total por causa do indício de reações expansivas que poderiam prejudicar determinadas aplicações. Assim, foi proposto o estudo das condições ideais de dosagem para mitigar os efeitos de tais reações pela presença de contaminantes destes rejeitos. Os resultados demonstraram a efetiva promoção de reações do tipo álcali-agregado, e que o uso de cimentos especiais poderá diminuir o efeito prejudicial dos subprodutos formados.
\end{abstract}

Palavras-chave: reciclagem secundária, rejeitos de porcelana elétrica, concreto, reações expansivas.

\begin{abstract}
The use of rubbish and other kinds of domestic and industrial wastes on civil construction has been a common practice in many developed countries, due either to the increase in the amount of waste and the resultant reduction of appropriate places to its final disposal, as well as to the severity and steadiness of environmental inspection organizations. In order to provide beforehand manners to solve or reduce these problems, study of recycling and co-disposal of waste from porcelain electrical insulators in concrete was proposed. Besides the occurrence of expansive reactions, which may be harmful to the stability of important structures, the overall results were encouraging. Some contaminants found in the three phases of porcelain contributed to the happening of alkali-aggregate reaction, which can easily inhibited by the using of special cements, such as a sulfur-resistant one.
\end{abstract}

Keywords: secondary recycling, electrical insulator porcelain waste, concrete, expansive reactions.

\section{INTRODUÇÃO}

Entulhos da construção civil e de outras indústrias tecnológicas que geram resíduos sólidos, principalmente, inertes, ainda têm o mesmo destino final que o do lixo doméstico, ou seja, os aterros sanitários. Dados estatísticos mostram que a geração de resíduos sólidos domésticos no Brasil, por dia, atinge números da ordem de $0,7 \mathrm{~kg} /$ habitante e, que destes, entre 41 e $70 \%$, são resíduos de construção e demolição (RCD) [1].

Não se tem uma estatística oficial do consumo anual geral de porcelanas elétricas produzidas e consumidas, porém, dados da $A B C$ [2], referentes a 2003, mostraram uma capacidade instalada de 44.000 t/ano, com produção anual de 28.000 t/ano. No Paraná há cerca de 160.000 km de linhas de redes de distribuição. Fazendo-se uma projeção de 60 isoladores de 1,2 kg/unidade (em média) e por $\mathrm{km}$ de linha, tem-se um passivo em torno de $11.000 \mathrm{t}$, considerando-se a vida útil destes componentes específicos. Apesar de ser inerte, este passivo torna-se um problema significativo e contribui, também, para o impacto ambiental.

Fazendo-se uma extrapolação para o Brasil, poderia se estimar um parque instalado 15 vezes maior. Deste número, considerando-se cerca de $8 \%$ a mais de resíduos gerados na própria fábrica, devido aos defeitos de queima, 
entre outros problemas de fabricação, o passivo estaria na ordem de 200.000 t. O teor é pequeno se comparado à demanda de recursos naturais, mas somando-se a outros resíduos de construção e demolição, haverá, anualmente, significativa diminuição dos rejeitos em aterros sanitários com a adoção de produtos ambientalmente corretos.

Tratando-se os isoladores de porcelana como agregados para concreto, por moagem nas dimensões normalmente utilizadas, algumas considerações devem ser feitas. O vidrado superficial das saias da porcelana e a própria porcelana podem ser potencialmente reativos com os cimentos comumente usados, produzindo reações expansivas, trincas e diminuição da resistência mecânica final. Os materiais de base podem conter ferro, cromo, manganês, zircônio, cobalto e níquel, para os vidrados nas cores marrom e cinza, bem como outros constituintes como quartzo, feldspato e caulim, que podem ser reativos ou vir a causar contaminação ambiental posterior [3-10].

Agentes cimentantes à base de enxofre, utilizados para fixação das ferragens às saias de isoladores, são componentes indesejados pela tendência em reagir com os álcalis do cimento e pela dificuldade em separálos da matéria-prima, elevando-se o custo final da imobilização.

Determinados compostos químicos ou íons, quando incorporados ao concreto, sejam no momento do amassamento ou posterior a este, por mecanismos de infiltração e difusão, são, normalmente, deletérios por causarem reações químicas expansivas. Como exemplo, têm-se: os materiais silicosos: opala, calcedônia, cristobalita e tridimita, zeólita, fenlandita, entre outras formas vítreas, incluindo o quartzo e o vidro (algumas composições básicas de silicatos), sendo que a cinética da reação depende de vários fatores, tais como temperatura e umidade; os íons de enxofre; e os cloretos. Assim, são descritos alguns tipos de reações químicas na literatura: reações álcali-agregado, álcali-sílica, álcali-silicato e álcali-carbonato, ataques por sulfatos e cloretos, etringita secundária, entre outros $[3,5]$.

Reação álcali-agregado, RAA, é o termo geral utilizado para descrever a reação química que ocorre internamente à estrutura de concreto, envolvendo os hidróxidos alcalinos provenientes, principalmente, do cimento e de alguns minerais reativos presentes no agregado utilizado ou da sua circunvizinhança. Neste caso específico, os produtos gerados podem aumentar de volume sob condições especiais de umidade e temperatura, criando tensões internas ao concreto e posterior fissuração, perda da monoliticidade e, conseqüentemente, comprometimento da estrutura [4-8].

A reação álcali-sílica, que ocorre a velocidades mais rápidas no concreto do que a álcali-silicato, é definida como uma reação ácido-base, onde o reagente ácido é a sílica no estado sólido e os reagentes básicos, os hidróxidos de potássio e sódio presentes na solução dos poros do concreto, sendo a água dos poros o meio onde ocorre a reação. Esta reação ocorre entre os álcalis e alguns tipos de silicatos eventualmente presentes em certas rochas sedimentares (argilitos, siltitos e grauvacas), rochas metamórficas (ardósias, filitos, xistos, gnaisses, granulitos, entre outras) e ígneas (granitos), sendo que neste caso a reação está, basicamente, ligada à presença de quartzo tensionado [4].

Na reação álcali-carbonato, as rochas dolomíticas são as principais envolvidas, havendo a desdolomitização, fenômeno no qual há a formação do hidróxido de magnésio.

Em situações onde os artefatos ou as estruturas de concreto armado estão expostos a atmosferas com elevada salinidade, os riscos de corrosão aumentam e são mais sérios, em virtude da presença de íons despassivantes, capazes de romperem a película protetora de óxidos que recobre as armaduras em um concreto com $\mathrm{pH}$ maior que 12,5. Os íons cloreto, quando presentes em quantidades importantes, podem causar a despassivação do aço, inclusive, em um meio de alto $\mathrm{pH}$, como é caso do concreto não-carbonatado.

A introdução do cloreto no concreto pode ocorrer durante a fabricação (como contaminante do cimento; com a água de amassamento, se forem utilizadas águas salobras; como componente do aditivo de cura, etc.) ou em serviço (como por exemplo, nas estruturas situadas próximas à orla marítima) [5-8]. Durante o serviço da estrutura, os íons cloreto que provêm de fontes externas podem difundir rapidamente na cobertura de concreto e atingir a armadura em um período de tempo muito mais curto que o correspondente à vida projetada da mesma. As fontes mais comuns são: os sais de degelo, a água de mar ou a atmosfera marinha e alguns processos industriais [11]. Este íon provoca um ataque do tipo localizado no aço das armaduras e a sua quantidade requerida para iniciar a corrosão depende do pH da solução contida nos poros do concreto e do traço utilizado.

Soluções contendo íons sulfato são, também, meios agressivos ao concreto, causando perda de resistência, expansões volumétricas, trincas e degradação. Expansões lineares próximas de $0,5 \%$ foram verificadas em argamassas em presença de solução contendo 1,8\% de sulfato de sódio, em poucas semanas [6]. Os íons sulfato reagem com o aluminato de cálcio, $\mathrm{C}_{3} \mathrm{~A}, \mathrm{e}$, havendo suficiente quantidade de água, dão lugar à etringita, fortemente hidratada, muito volumosa e expansiva. Este material provoca a fissuração do concreto, facilitando posterior penetração de agentes agressivos, além de propiciar a uma redução da resistência à compressão [5, 6].

A etringita primária é um mineral comumente encontrado no concreto e não causa muitos danos ao mesmo. Porém, a etringita secundária, presente na forma de cristais aciculares formados em virtude de alguns fatores químicos e ambientais após a cura completa 
do concreto e ao longo do tempo, é a mais prejudicial, por envolver produtos de grande volume e altamente expansíveis no interior da estrutura. A sua formação, normalmente, vem acompanhada de fissuração do concreto [5].

\section{EXPERIMENTAL}

A metodologia deste projeto está concentrada na determinação de parâmetros para identificar a contribuição dos subprodutos do enxofre presente na argamassa ou concreto com rejeitos de porcelanas elétricas, vidrado e da própria porcelana. Para o desenvolvimento do presente projeto, foram empregados os seguintes materiais:

a) cimentos

- cimento Portland composto com adição de fíler carbonático, tipo CPII-F 32, com resistência característica de 32 MPa (mín.), aos 28 d; e

- cimento Portland de alta resistência inicial, tipo CPV-ARI RS, resistente a sulfatos.

b) agregados

- agregados graúdos - brita 1 e brita 0 (pedrisco);

- agregado miúdo - areia natural lavada; e

- rejeitos de porcelana moídos nas granulometrias menores que $19 \mathrm{~mm}$ e classificados por faixas granulométricas.

As dosagens ideais corresponderam a substituições parciais de agregados naturais por rejeitos de porcelana em um limite máximo de $80 \%$, sendo os mais indicados entre 20 e 50\% [12]. Para este estudo, foram selecionados três traços e moldados CP's dos mesmos, sendo: concreto-referência contendo 100\% de agregados naturais, códigos E-1740 e E-1758; traço com 50\% de agregados artificiais (graúdos e miúdos) em substituição aos agregados naturais, códigos E-1741 e E-1759, e; concreto com $100 \%$ de agregados graúdos artificiais e 100\% de agregados miúdos naturais, códigos E-1757 e E-1760. Para cada traço foram confeccionadas duas dosagens, utilizando os cimentos CPII-F 32 e CPV-ARI RS, respectivamente.

A seguir, estão descritas as principais técnicas analíticas consideradas indispensáveis para o atendimento dos objetivos propostos.

1. Microscopia eletrônica de varredura e microanálise (MEV e EDS). Ensaios executados em CP's, previamente metalizados com ouro em sua superfície de fratura, para verificar a micrografia e a composição química do material.

2. Espectrofotometria de absorção atômica (AA) e cromatografia de íons (CI). Técnicas utilizadas para a análise química elementar dos cátions: $\mathrm{Al}, \mathrm{Ca}, \mathrm{Si}, \mathrm{Na}$, $\mathrm{K}$, Fe, Ti e Mg, que são os principais constituintes do cimento. Análise química complementar foi feita por intermédio de equipamento de fluorescência de raios X (FRX), usando a técnica de preparo da amostra em pastilha de bórax.

3. Análises termodiferencial e termogravimétrica (DTA e TGA). Técnicas usadas para verificar as mudanças de calor e perdas ou ganhos de massa envolvidos na formação dos subprodutos decorrentes da reatividade potencial ou, também, pelo processo de queima do material à temperatura elevada. Pó da argamassa foi retirado por pulverização, após fratura do CP.

4. Difração de raios X (DRX). Ensaio executado em amostras pulverizadas da argamassa, extraídas dos CP's fraturados, tendo como objetivo identificar as fases cristalinas presentes.

5. Propriedades elétricas. A técnica de potencial de corrosão da armadura metálica foi aplicada com o objetivo de analisar as propriedades elétricas do metal da armadura dos CP's de concreto ao longo do envelhecimento acelerado. Para tanto, o potencial de corrosão considerado em cada medida foi o potencial de repouso obtido no início do ensaio, e após um período de envelhecimento superior a $120 \mathrm{~d}$ em dois banhos: i) em solução de nitrato de amônio a 5,5\%; e ii) em solução mista de cloreto de sódio a 3,4\% com sulfato de sódio a $2,1 \%$, ambos na temperatura de $(23 \pm 2){ }^{\circ} \mathrm{C}$.

Como a principal função prevista para estes CP's, além da avaliação da degradação do concreto, foi o estudo da corrosão das armaduras, fez-se necessária a inclusão de barras de aço. Tais barras funcionaram como eletrodos metálicos para auxiliar nas medidas citadas.
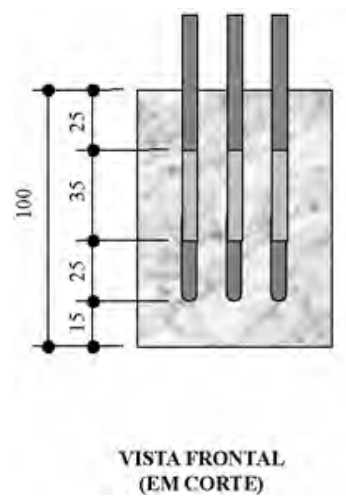

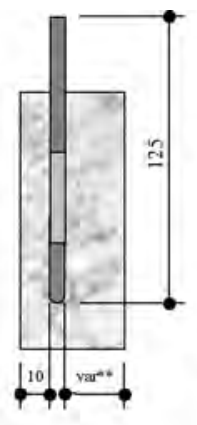

VISTA LATERAL (EM CORTE)

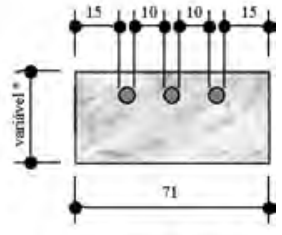

VISTA SUPERIOR
Figura 1: Desenho esquemático ilustrativo da geometria e dimensões dos CP's para as medidas elétricas.

[Figure 2: Scheme of the geometry and dimensions of concrete samples used for electrical measurements.]

O eletrodo de referência utilizado foi o eletrodo de calomelano saturado (ECS). O contato do eletrodo com as superfícies superiores dos CP's foi feito com almofadas de feltro, embebidas em água destilada. Todos os potenciais de eletrodo foram referidos ao ECS. Os parâmetros para todas as medidas foram os mesmos, comumente utilizados em determinações elétricas por espectrometria de impedância eletroquímica, EIS, uma 
vez que a técnica, também, foi aplicada para a obtenção de outros parâmetros elétricos do sistema [12], sendo: freqüência inicial de 50 kHz; freqüência final de $10 \mathrm{mHz}$; amplitude (rms) de $5 \mathrm{mV}$; sendo ensaiados na temperatura ambiente de $(23 \pm 2){ }^{\circ} \mathrm{C}$.

Um desenho esquemático, indicando a geometria e dimensões dos CP's de concreto conformados, bem como a disposição das armaduras, está apresentado na Fig. 1.

6. Ensaios físico-químicos nas matérias-primas. As técnicas empregadas tiveram como objetivo caracterizar e qualificar por análises físico-químicas os materiais utilizados no estudo.

7. Estudo de reatividade. O objetivo foi o de avaliar quais fases químicas presentes na porcelana são as mais reativas: a cerâmica branca micro-porosa, que constitui a parte interna dos isoladores de porcelana; o vidrado superficial, de cor cinza ou marrom, impermeável, que envolve a cerâmica branca; e o agente cimentante à base de enxofre, utilizado na fixação das ferragens à saia do isolador. Desta forma, para propiciar uma avaliação precisa da reatividade dos agregados cerâmicos artificiais (isoladores de porcelana britados), foram selecionadas quatro parcelas distintas: agregado com vidrado, contendo enxofre; agregado com vidrado, não contendo enxofre; agregado sem vidrado, contendo enxofre; e agregado sem vidrado, não contendo enxofre. Todos os materiais de cada parcela foram separados a olho nu, o que significa, apesar de pequena, a possibilidade de um percentual de contaminantes em cada fase correspondente. Os
CP's foram confeccionados e avaliados, de acordo com procedimentos de normas em 8 traços distintos [12-14]. Para cada uma das oito composições foram moldados 5 CP's prismáticos (barras) de dimensões (25 x 25 x 300) $\mathrm{mm}$, os quais foram mantidos nas condições de ensaio até 7, 14, 28 e 91 d, sendo então rompidos para a realização das análises por MEV e EDS. O ensaio constituiu-se, basicamente, da imersão dos CP's prismáticos de concreto em solução de $\mathrm{NaOH} 1 \mathrm{~N}$, a $80^{\circ} \mathrm{C}$, por $28 \mathrm{~d}$, de forma a infligir um envelhecimento acelerado ao material. Diariamente, cada amostra teve seu comprimento medido, a fim de se conhecer sua dilatação linear (expansão). Alteração da temperatura de ensaio de $80{ }^{\circ} \mathrm{C}$ para $23{ }^{\circ} \mathrm{C}$ foi realizada afim de verificar sua influência na expansão final dos CP's, durante o ensaio.

8. Propriedades mecânicas. Foram realizados ensaios de resistência à compressão axial simples, módulo de deformação estática secante, resistência à tração por compressão diametral e resistência à tração na flexão, de acordo com as recomendações de normas [13-18] e entre 91 d de cura úmida.

\section{RESULTADOS E DISCUSSÃO}

Todos os agregados naturais utilizados foram previamente analisados, chegando-se à conclusão pela continuidade do estudo por não haver influência negativa direta, nas propriedades mecânicas analisadas [12].

Os resultados das análises físico-químicas, obtidos

Tabela I - Características físico-químicas dos concretos confeccionados com os cimentos CPII-F 32 e CPV-ARI RS. [Table I - Physicochemical characteristics of concretes made with CPII-F 32 and CPV-ARI RS cements.]

\begin{tabular}{|c|c|c|c|c|c|c|}
\hline \multirow[t]{2}{*}{ Dosagem } & \multicolumn{3}{|c|}{ CPII-F 32} & \multicolumn{3}{|c|}{ CPV-ARI RS } \\
\hline & $\begin{array}{c}\mathrm{E}-1740 \\
(1)\end{array}$ & $\begin{array}{c}\text { E-1741 } \\
(2)\end{array}$ & $\begin{array}{c}\text { E-1757 } \\
\text { (3) }\end{array}$ & $\begin{array}{c}\text { E-1758 } \\
\quad(4)\end{array}$ & $\begin{array}{l}\text { E-1759 } \\
\quad(5)\end{array}$ & $\begin{array}{c}\text { E-1760 } \\
(6)\end{array}$ \\
\hline $\mathrm{a} / \mathrm{c}$ & 0,5 & 0,5 & 0,5 & 0,5 & 0,5 & 0,5 \\
\hline $\mathrm{D}_{\text {máx }}, \mathrm{mm}$ & 19 & 19 & 19 & 19 & 19 & 19 \\
\hline $\begin{array}{l}\text { Teor de agregado miúdo, \% } \\
\text { Consumos, } \mathrm{kg} / \mathrm{m}^{3}\end{array}$ & 40,4 & 40,4 & 40,4 & 40,4 & 40,4 & 40,4 \\
\hline cimento & 360 & 347 & 344 & 358 & 343 & 342 \\
\hline areia natural & 728 & 351 & 695 & 724 & 347 & 691 \\
\hline areia artificial & - & 351 & - & - & 347 & - \\
\hline brita natural & 1073 & 518 & - & 1067 & 512 & - \\
\hline brita artificial & - & 518 & 1026 & - & 512 & 1020 \\
\hline água & 184 & 177 & 176 & 183 & 175 & 175 \\
\hline Abatimento, mm & 55 & 15 & 17 & 37 & 25 & 22 \\
\hline Massa unitária, $\mathrm{kg} / \mathrm{m}^{3}$ & & & & & & \\
\hline teórica & 2366 & 2284 & 2263 & 2354 & 2272 & 2251 \\
\hline real & 2332 & 2251 & 2230 & 2325 & 2219 & 2221 \\
\hline Ar incorporado, \% & 0,5 & 1,0 & 0,5 & 1,0 & 0,5 & 1,0 \\
\hline Temperatura do concreto, ${ }^{\circ} \mathrm{C}$ & 21,1 & 22,7 & 22,9 & 22,4 & 21,5 & 21,5 \\
\hline
\end{tabular}




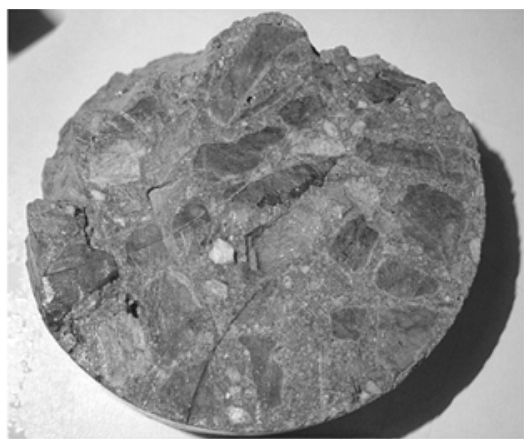

(a)

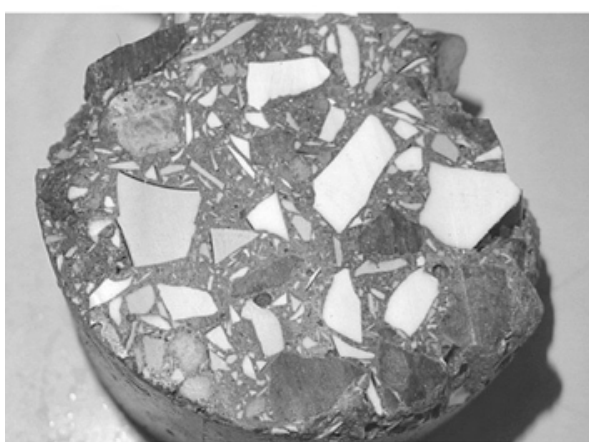

(b)

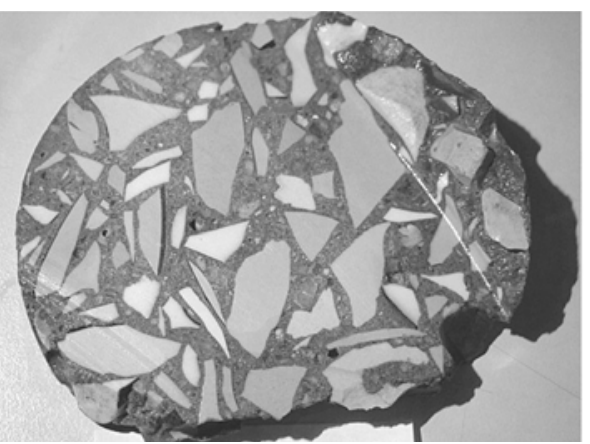

(c)

Figura 2: Imagens das superfícies de corte dos CP’s de concreto fabricados, sendo: (a) concreto-referência; (b) concreto com 50\% areia natural/areia artificial e 50\% de brita 1/agregado artificial britado; e (c) concreto com 100\% agregado graúdo artificial britado e $100 \%$ de areia natural.

[Figure 2: Images of fracture surfaces of concrete samples, as follow: (a) reference concrete; (b) concrete containing 50\% natural sand/artificial sand and 50\% natural coarse aggregate lartificial crushed aggregate; and (c) concrete with 100\% artificial crushed coarse aggregate and 100\% natural sand.]

para ambos os cimentos, encontraram-se dentro das especificações e recomendações do fabricante e das normas vigentes [19-20].

$\mathrm{Na}$ Tabela I, estão indicadas informações sobre os concretos obtidos na etapa de dosagens. Algumas propriedades das misturas frescas, também, estão apresentadas. Os traços elaborados apresentaram consistências (medidas pelo abatimento de tronco de

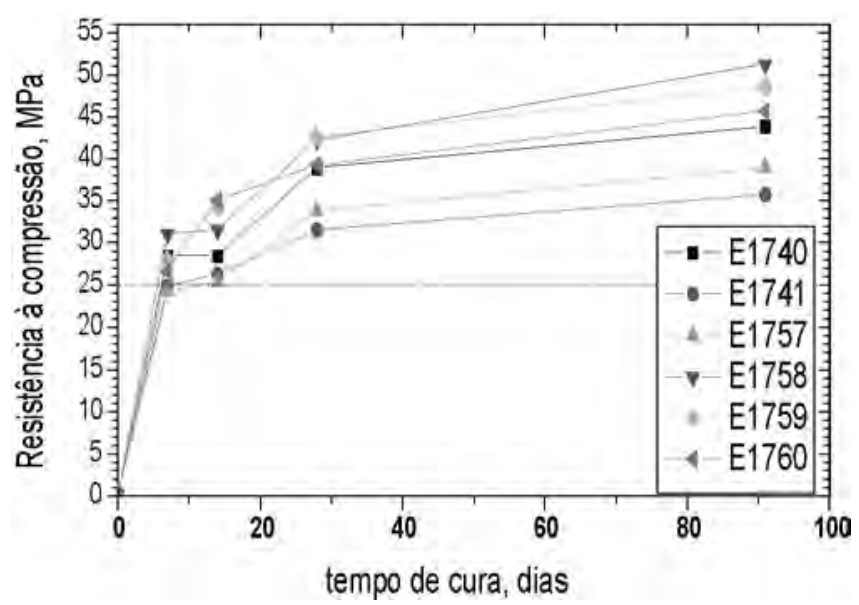

Figura 3: Resistência mecânica à compressão dos traços de concreto fabricados com e sem porcelana.

[Figure 3: Compressive strength of concrete mixtures made with and without porcelain waste]. cone, slump) dentro do esperado para a conformação de estruturas não muito complexas, tais como para os artefatos de concreto armado para redes de distribuição de energia elétrica (postes, contrapostes, cruzetas e placas de estai). A manipulação de tais traços não apresentou segregação nociva.

A incorporação dos rejeitos de porcelana aos concretos, em substituição aos agregados naturais, promoveu uma redução de, aproximadamente, 5\% do consumo de cimento, sendo economicamente viável, uma vez que o aglomerante, geralmente, é o insumo de maior custo no concreto. Uma visão geral da superfície de corte de alguns CP's confeccionados pode ser vista na Fig. 2.

Os valores médios resultantes em resistência mecânica à compressão nos 91 d de cura úmida, encontram-se mostrados no gráfico da Fig. 3. Foi considerado como limite mínimo o valor de $25 \mathrm{MPa}$ recomendado pela NBR 8451/85 [21], para postes de concreto armado para redes de distribuição. Todas as misturas apresentaram resistências acima deste limite já aos 14 d de idade, o que indicou um bom desempenho mecânico dos concretos confeccionados.

As maiores resistências foram obtidas para os traços preparados com cimento CPV-ARI RS. A justificativa para o melhor resultado destes traços está na maior finura (Blaine) do cimento e, também, na inibição de ataques por sulfato devido ao uso deste cimento especial,

Tabela II - Resistência mecânica à tração por compressão diametral e na flexão dos concretos, aos $28 \mathrm{~d}$ de cura. [Table II - Tension strengths, at 28 days of curing, of studied concretes.]

\begin{tabular}{lcccccc}
\hline \multicolumn{1}{c}{ Dosagem } & E-1740 & E-1741 & E-1757 & E-1758 & E-1759 & E-1760 \\
\hline Resistência à tração por & & & & & & \\
compressão diametral, MPa & 2,6 & 2,6 & 2,6 & 3,2 & 3,6 & 3,4 \\
Resistência à tração na flexão, MPa & 3,9 & 4,0 & 4,3 & 4,4 & 4,7 & 4,3 \\
\hline
\end{tabular}


já que nas dosagens com agregado artificial, existem muitos finos com este contaminante. Os resultados da resistência à tração por compressão diametral e tração na flexão, aos 28 d, dos CP's com as referidas dosagens estão apresentados na Tabela II.

Os valores verificados para a resistência à tração estão entre 7 e 13\% dos resultados de resistência à compressão, permanecendo dentro dos valores encontrados na literatura [7].

A curva tensão-deformação, obtida aos 28 d de cura, para cada traço estudado está apresentada na Fig. 4. Os valores médios obtidos para as composições com agregados artificiais, medidos pelo módulo secante, para os traços com cimento CPV-ARI RS, foram ligeiramente superiores ao concreto-referência, sendo constatado o inverso para as composições produzidas com o cimento CPII-F 32. Valores da mesma ordem de grandeza dos apresentados na Fig. 4 são mostrados por Mehta e Monteiro [7], para concretos de peso normal e agregados à base de quartzo. Como tal propriedade está relacionada, também, com o tipo de agregado e seu módulo de deformação, os valores observados são plenamente justificados para concretos com rejeitos de porcelana, que têm a característica de possuir baixa porosidade e alto módulo de deformação.

Na Fig. 5 estão mostradas curvas de reatividade potencial dos CP's confeccionados com diferentes combinações de fases da porcelana: vidrado, argamassa de enxofre e cerâmica branca. Desta análise, pode-se destacar:

1. nos primeiros $28 \mathrm{~d}$ de teste, as composições com cimento CPV-ARI RS apresentaram maior resistência à expansão do que aquelas com CPII-F 32;

2. para os traços com cimento CPII-F 32, indicados por $\mathrm{A}$, as maiores expansibilidades foram observadas nas amostras com vidrado e enxofre, seguidas dos traços sem vidrado e sem enxofre, com vidrado e sem enxofre e, finalmente, sem vidrado e com enxofre. Destes resultados

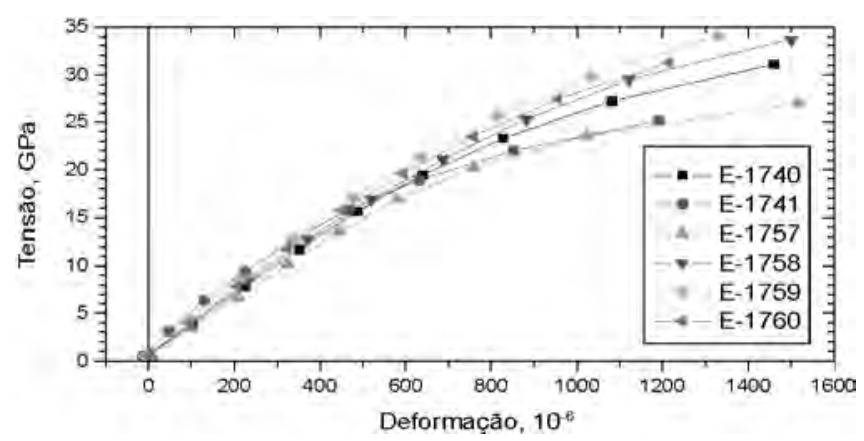

Figura 4: Curvas de tensão-deformação, aos 28 d de cura, dos traços de concreto estudados.

[Figure 4: Stress-strength diagrams, at 28 days of curing, of the studied concrete mixtures.]

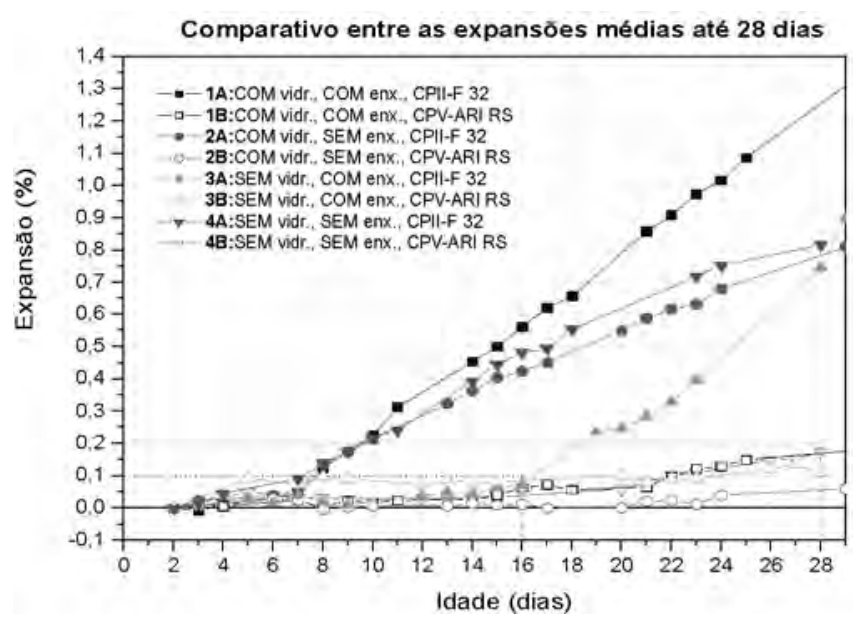

Figura 5: Análise da reatividade potencial de CP’s de concreto com agregados artificiais, até $28 \mathrm{~d}$.

[Figure 5: Potential reactivity of concrete samples containing artificial porcelain aggregates up to $28 \mathrm{~d}$ of accelerated ageing.]

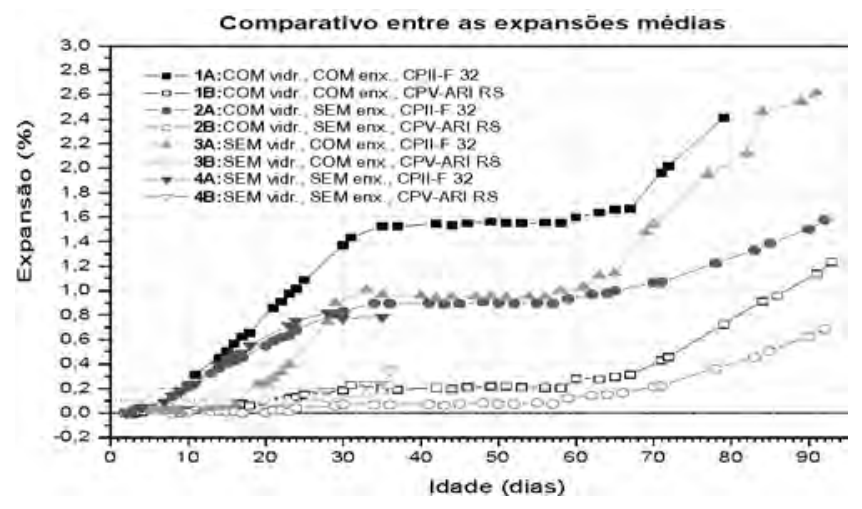

Figura 6: Reatividade potencial das amostras em função da temperatura e do tempo de envelhecimento.

[Figure 6: Influence of temperature on potential reactivity of concrete samples, in terms of ageing time.]

pode-se considerar que o enxofre, no período considerado, possuiu pouca influência na expansibilidade resultante e que a maior influência foi da própria massa de porcelana moída, ou seja, a massa com maior concentração de sílica reativa.

3. para a composição com cimento CPV-ARI RS, indicada por $B$, no período analisado, não houve expansibilidade além dos limites estabelecidos como normais, pela norma ASTM C1260-94 [13]. Isto demonstra a efetividade do cimento na redução das reações expansivas, para o período analisado.

Ao longo do tempo de envelhecimento, conforme gráfico apresentado na Fig. 5, pôde-se observar, para a composição com enxofre e cimento CPII-F 32, a maior participação deste elemento químico na expansibilidade resultante. A expansão total da composição com vidrado 

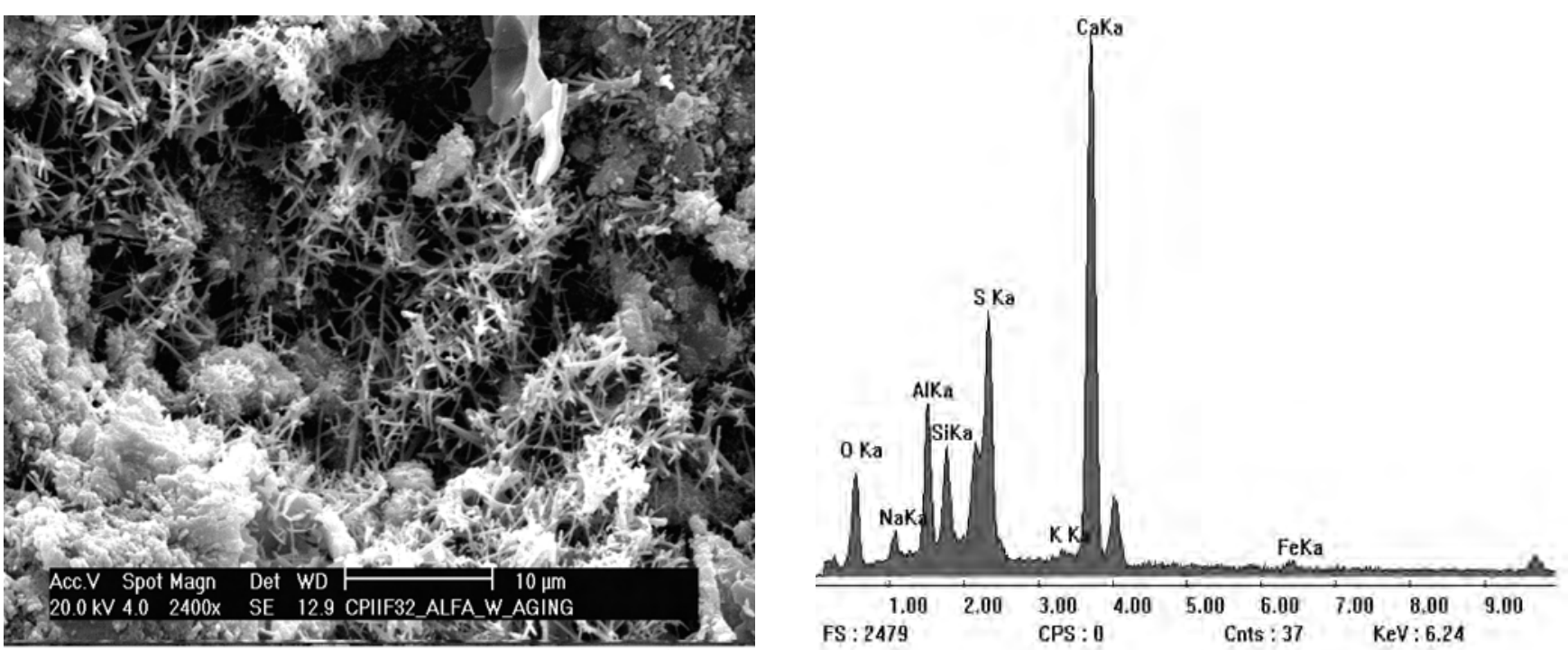

Figura 7: Micrografia, por MEV, da superfície de fratura do concreto com cimento Portland CPII-F 32 e espectro EDS da região. [Figure 7: SEM micrograph, with respective EDS spectre, of fracture surface of the concrete sample made with CPII-F 32 Portland cement.]
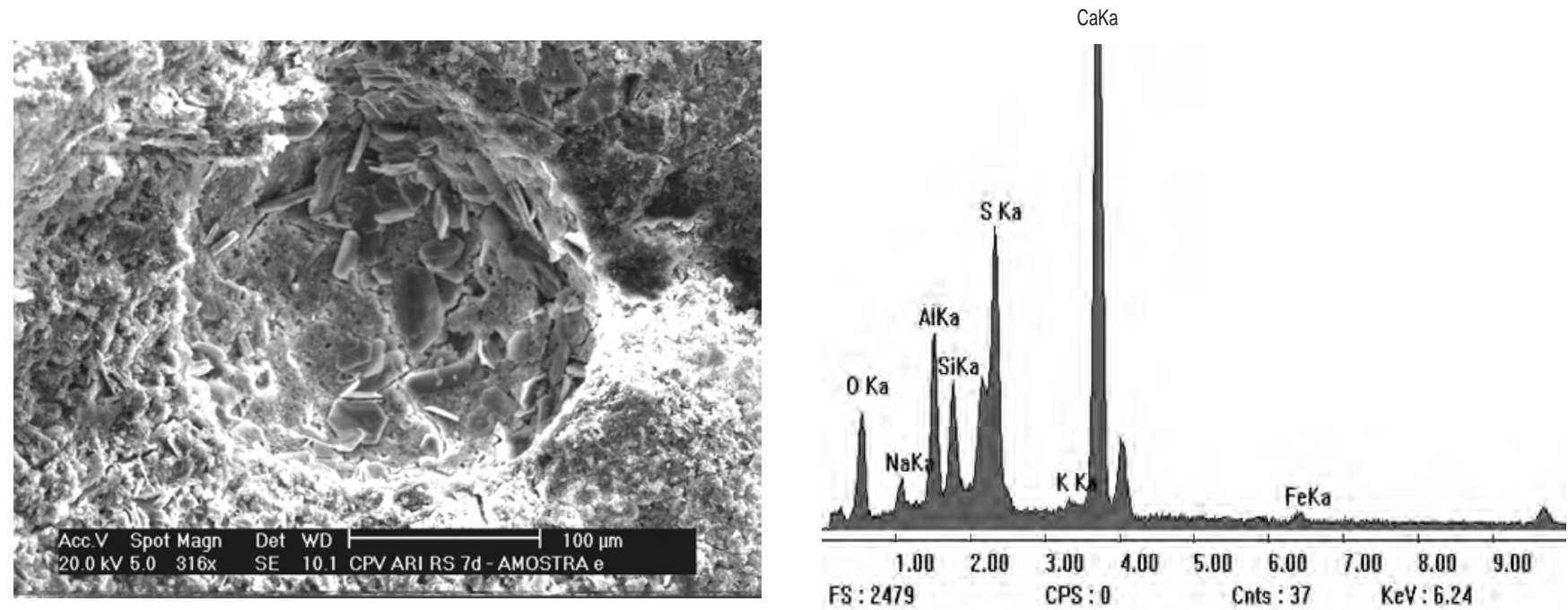

Figura 8: Micrografia, por MEV, e EDS da superfície de fratura do concreto com CPV-ARI RS 32, após 7 d de exposição em banho alcalino a $80{ }^{\circ} \mathrm{C}$. [Figure 8: SEM micrograph and EDS spectre of fracture surface of the concrete sample made with CPV-ARI RS Portland cement, after 7 days of ageing in a alkaline bath at $80^{\circ} \mathrm{C}$.]

à base de sílica reativa foi superada a partir dos $28 \mathrm{~d}$. As composições "sem vidrado e sem enxofre" e "sem vidrado e com enxofre" não puderam ser analisadas, por motivos de perda de identificação. Mesmo assim, destaca-se que o material reciclado apresentou maior expansibilidade resultante em ambos os casos.

Outro fator importante observado nos resultados diz respeito à cinética da reação em função da temperatura do banho. A $23{ }^{\circ} \mathrm{C}$, todas as reações de envelhecimento estabilizaram, conforme patamar observado nas curvas de todas as amostras, entre 30 e $60 \mathrm{~d}$, conforme mostrado na Fig. 6. Após, com a alteração e retorno da temperatura do banho para $80{ }^{\circ} \mathrm{C}$, obteve-se, praticamente, a mesma inclinação inicial do processo.

Na Fig. 7, pode ser visualizada micrografia da amostra do concreto-referência com cimento CPII-F 32, onde se observa uma estrutura bastante entrecruzada de etringita. O espectro por EDS confirmou a presença de enxofre na região analisada.

No concreto-referência com cimento CPV-ARI RS não foram observados cristais de etringita na superfície de fratura, nas mesmas condições de teste.

Na Fig. 8 está mostrada a superfície de fratura de CP de concreto com cimento Portland CPV-ARI RS, contendo agregado artificial de porcelana, vidrado e enxofre na composição, ou seja, traço com maior reatividade estudado 


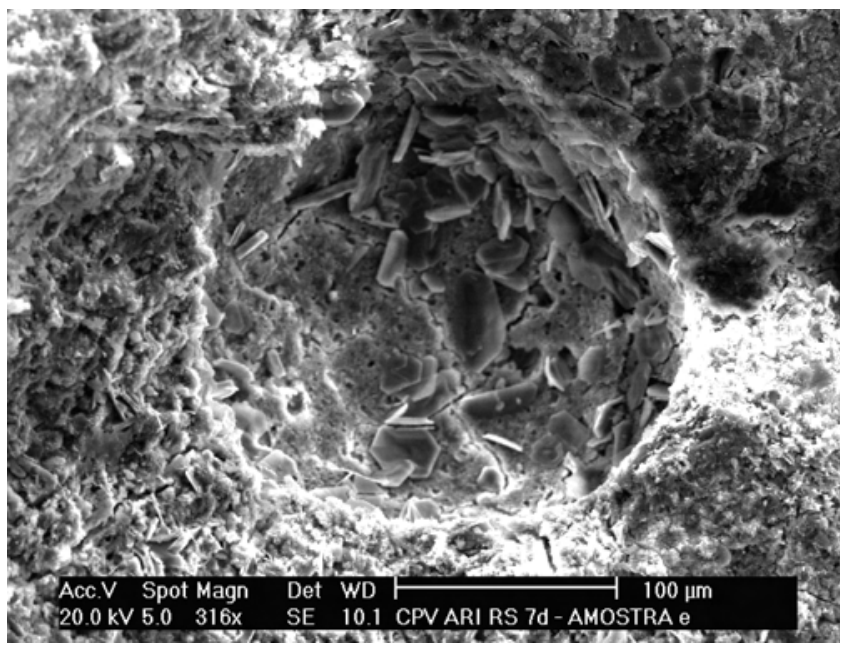

$7 \mathrm{~d}$

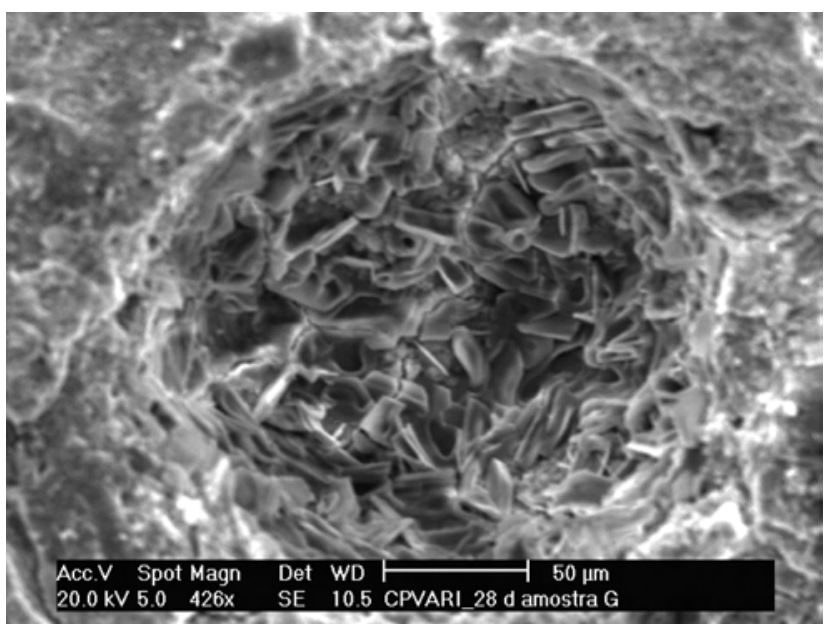

$28 \mathrm{~d}$

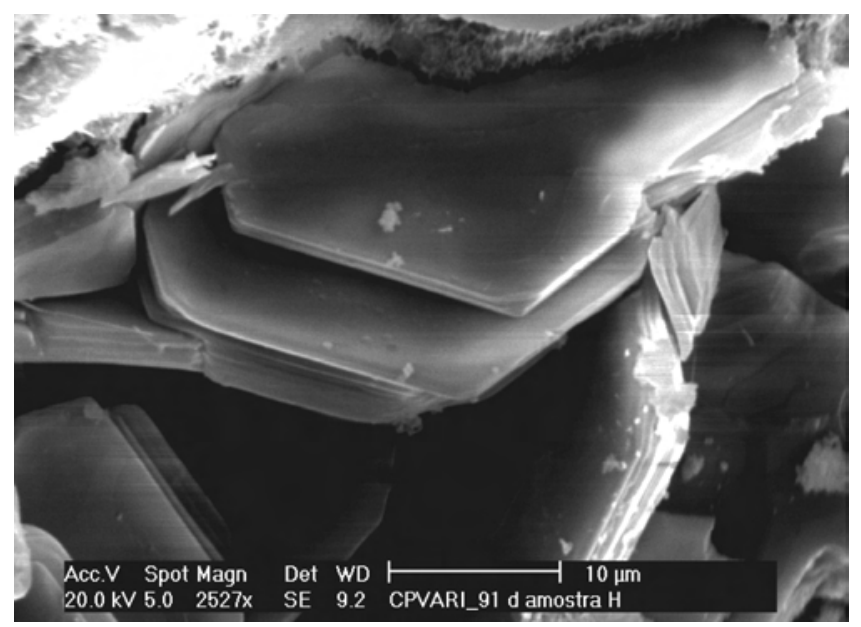

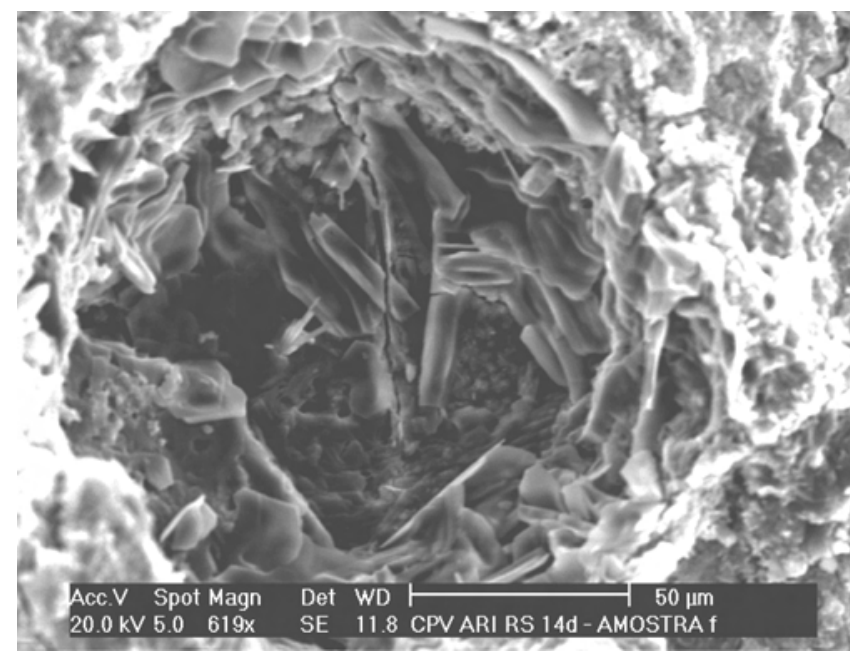

$14 \mathrm{~d}$

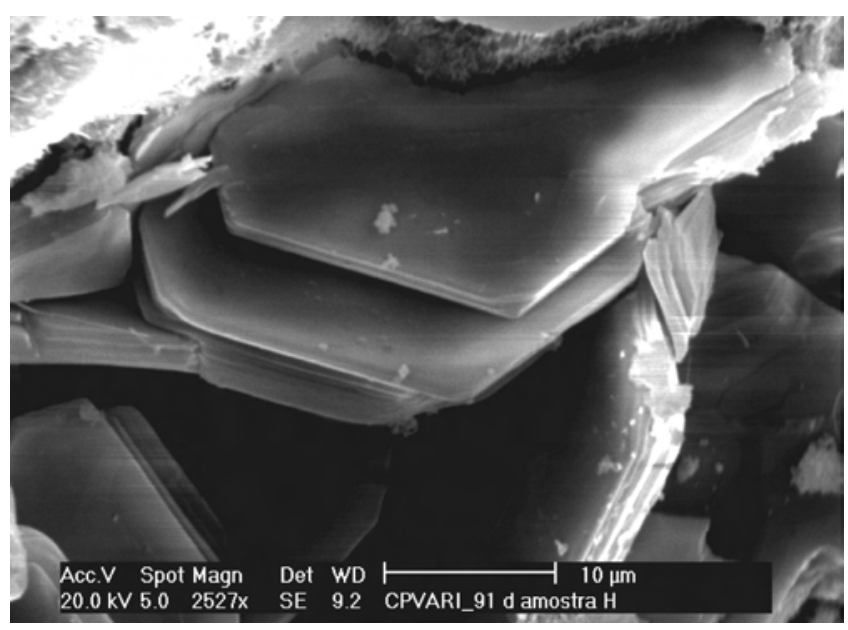

$91 \mathrm{~d}$

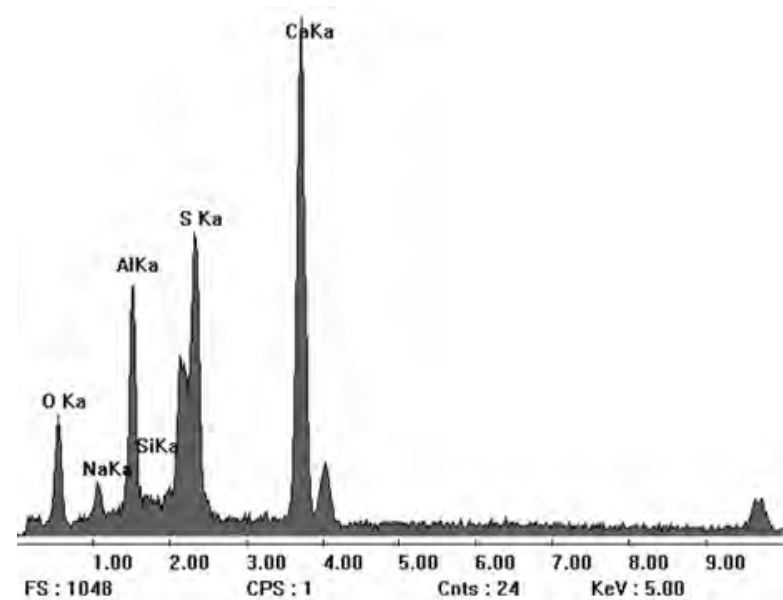

Figura 9: Micrografias, por MEV, das superfícies de fratura do concreto com cimento Portland CPV-ARI RS, de 7 a 91 d de exposição ao banho alcalino a $80^{\circ} \mathrm{C}$.

[Figure 9: SEM micrographs of fracture surface of the concrete sample made with CPV-ARI RS Portland cement, from 7 to $91 \mathrm{~d}$ of ageing times in a alkaline bath at $80^{\circ} \mathrm{C}$.] 

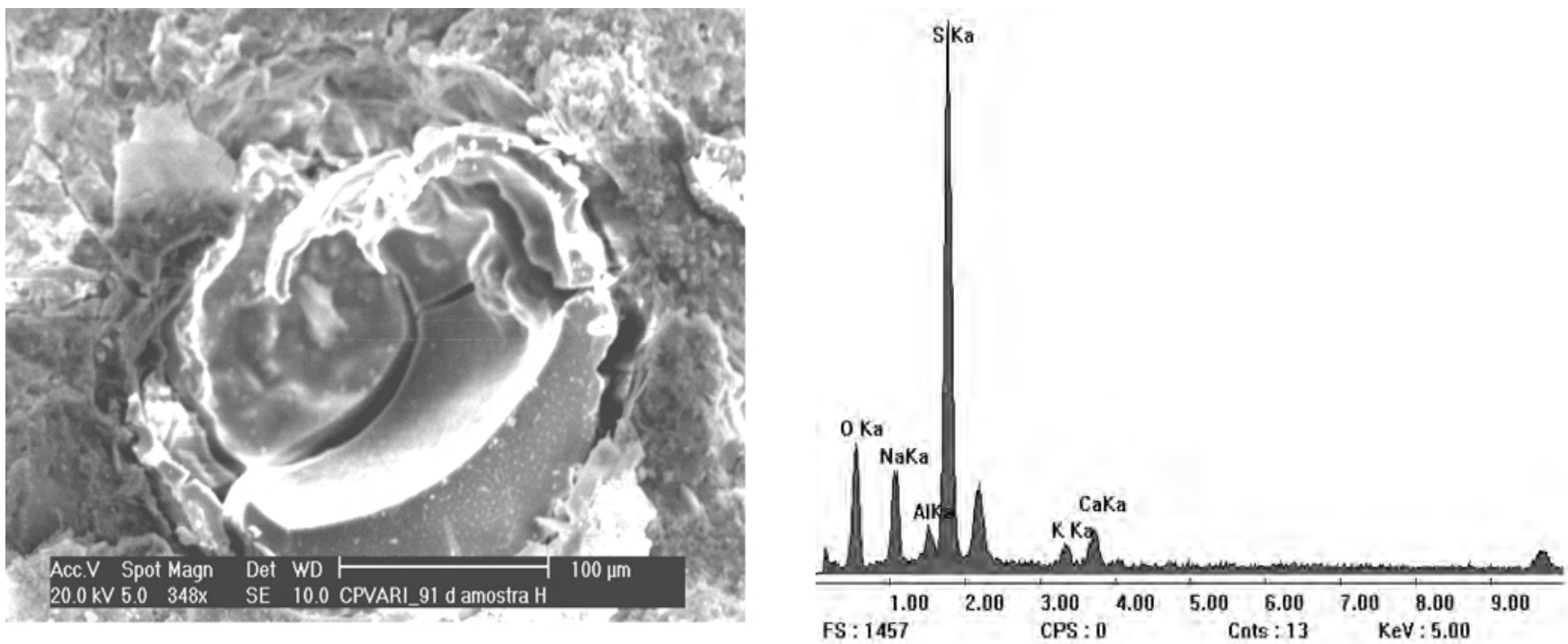

Figura 10: Micrografia, por MEV, e EDS da superfície de fratura do concreto com CPV-ARI RS, aos 91 d de exposição em banho alcalino a $80{ }^{\circ} \mathrm{C}$. [Figure 10: SEM micrograph and EDS spectre of fracture surface of the concrete sample made with CPV-ARI RS Portland cement, after 91 days of ageing in a alkaline bath at $80^{\circ} \mathrm{C}$.]
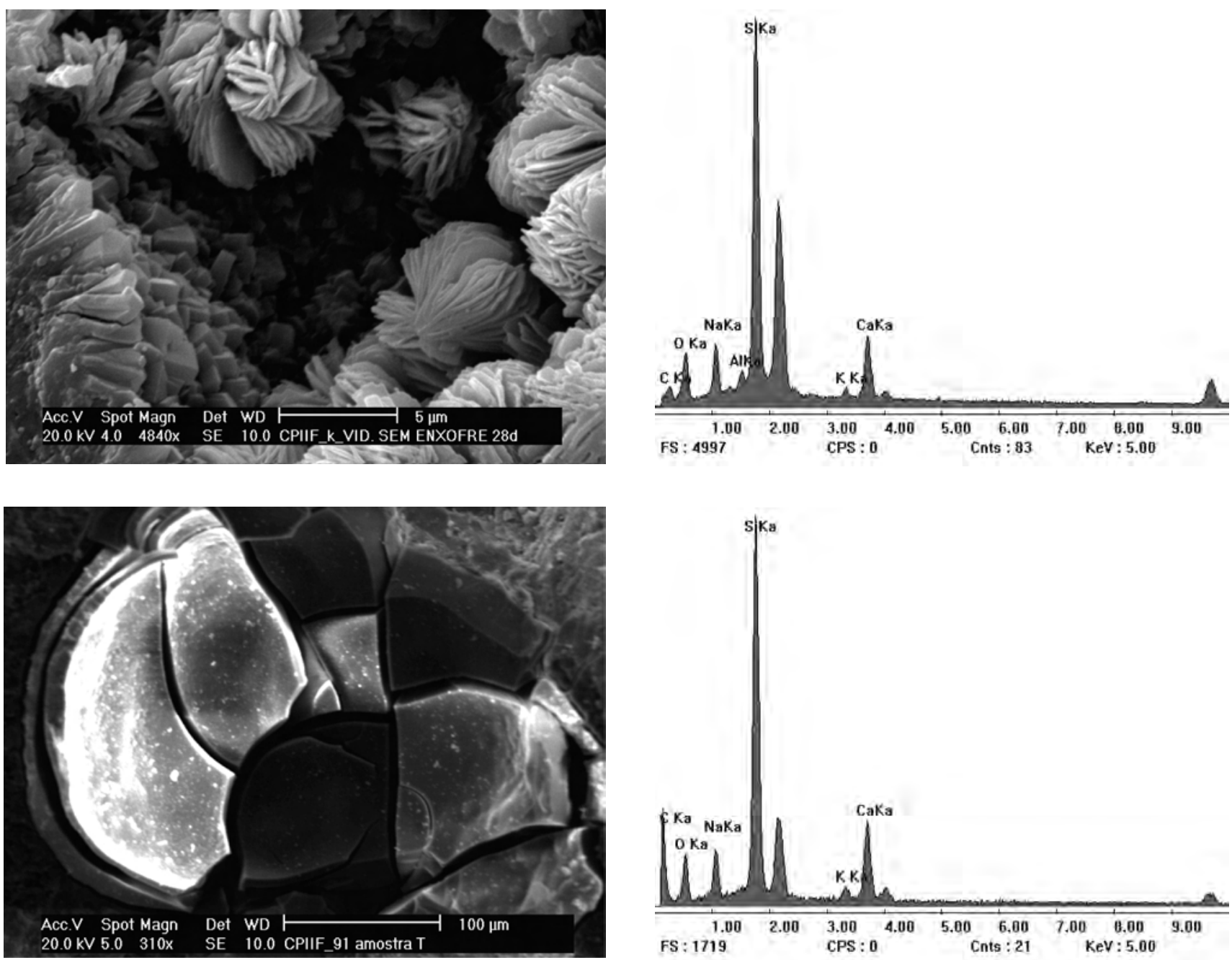

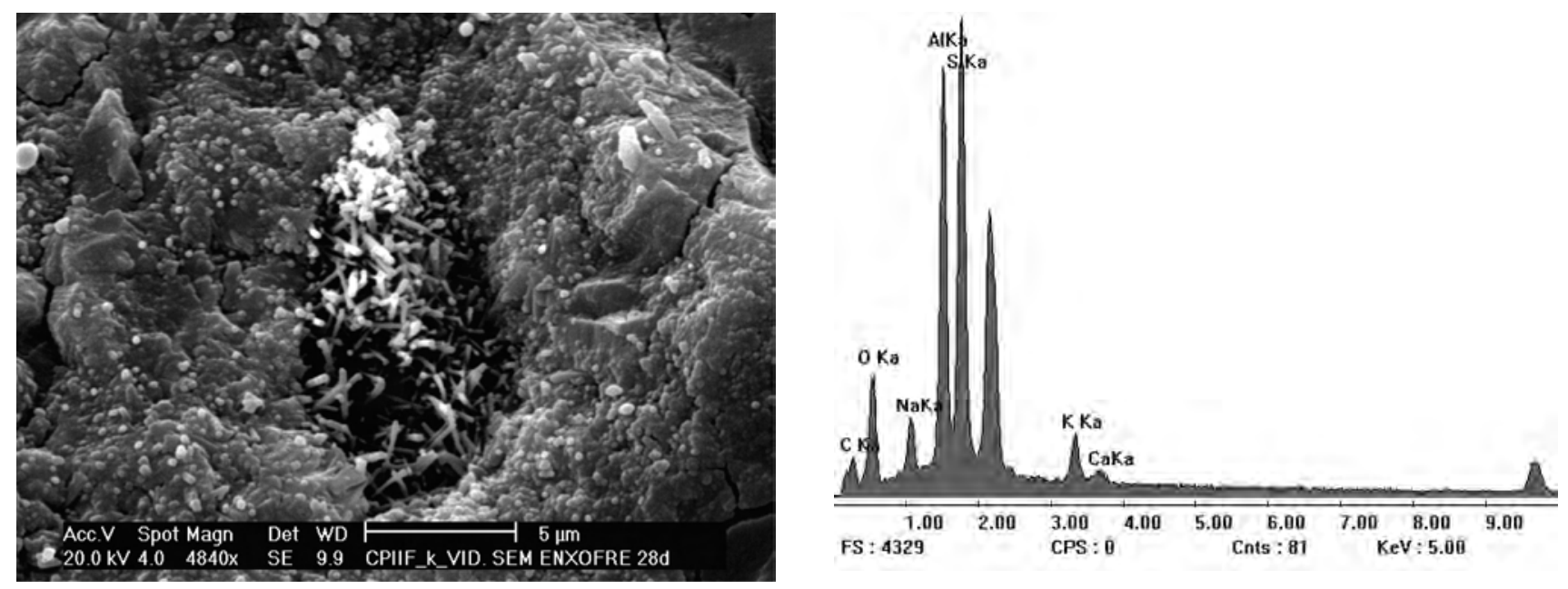

Figura 11: Micrografias, por MEV, do concreto com cimento Portland CPII-F 32, e análises químicas complementares das regiões inspecionadas, por EDS. [Figure 11: SEM micrographs, with respective EDS spectra, of fracture surface of the concrete sample made with CPII-F 32 Portland cement.]

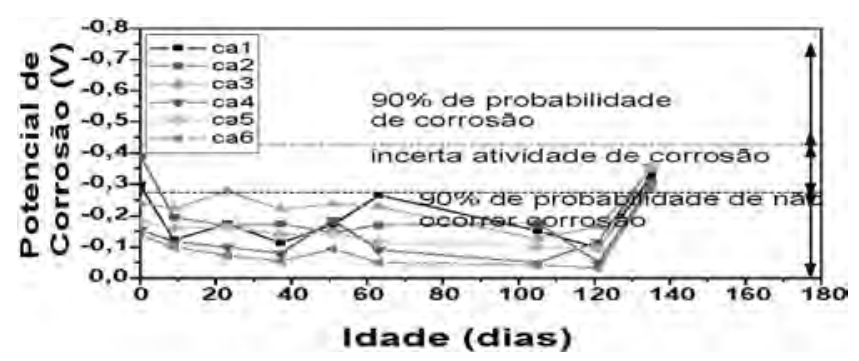

Figura 12: Curvas de potencial de corrosão dos CP’s curados em banho a $38{ }^{\circ} \mathrm{C}$ e envelhecidos em solução amoniacal, código ca, sendo: do 1 ao 3 correspondentes ao traço com cimento CPII-F 32 e, do 4 ao 6, com cimento CPV-ARI RS.

[Figure 12: Corrosion potential curves of concrete samples, after curing in a warm bath $\left(38^{\circ} \mathrm{C}\right)$ and ageing in an ammonium solution, coded ca, being: ca1 to ca3 - concretes made with CPII-F 32 cement; ca4 to ca6 - concretes made with CPV-ARI RS cement.]

e, após 7 d de exposição ao banho alcalino de $\mathrm{NaOH}$ a $80^{\circ} \mathrm{C}$. A estrutura visualizada é, possivelmente, um monossulfato, com mistura de cristais hexagonais de portlandita. Infelizmente, como a técnica não é quantitativa para os materiais analisados, não houve possibilidade de elaborar o seu cálculo estequiométrico. Esta composição é encontrada em boa parte dos macroporos observados.

Com a continuidade do ensaio, neste mesmo traço, foi verificado que o teor destes constituintes nos macroporos tendeu a aumentar, tanto em quantidade quanto em tamanho, conforme ilustrado na Fig. 9. Aos 91 d, foi bem evidenciada em toda a superfície de fratura e, principalmente, nos macroporos, grande quantidade de gel gretado, não sendo tão evidente em tempos inferiores. Este tipo de micrografia está mostrado na Fig. 10.

Pelos gráficos das Figs. 5 e 6 pode-se concluir que a reatividade potencial foi mais acentuada nos CP's com cimento Portland tipo CPII-F 32, do que no CPV-ARI RS. As imagens por MEV, mostradas na Fig. 11, com seus

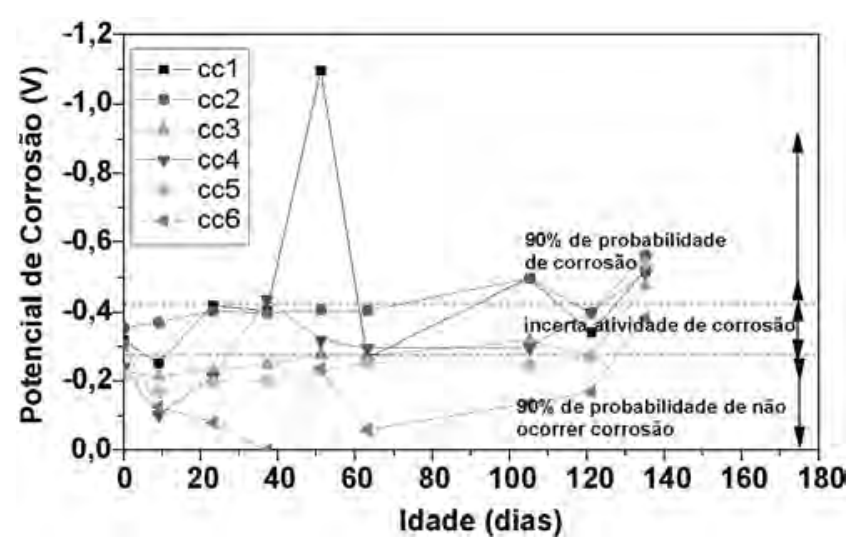

Figura 13: Curvas de potencial de corrosão dos CP’s curados em banho a $38{ }^{\circ} \mathrm{C}$ e envelhecidos em solução de 3,4\% de cloreto de sódio e 2,1\% de sulfato de sódio, cc, sendo: do 1 ao 3, correspondentes ao traço com cimento CPII-F 32 e, do 4 ao 6, com cimento CPV-ARI RS.

[Figure 13: Corrosion potential curves of concrete samples, after curng in a warm bath $\left(38^{\circ} \mathrm{C}\right)$ and ageing in an aqueous solution containing $3.4 \%$ sodium chloride and $2.1 \%$ sodium sulphate, coded cc, being: $c c 1$ to cc3 - concretes made with CPII-F 32 cement; cc4 to cc6 - concretes made with CPV-ARI RS cement.]

respectivos espectros por EDS, corroboram tais resultados, sendo que já nos primeiros dias de imersão no banho alcalino, foram obtidas tais imagens. Observam-se microestruturas de gel sílico-cálcico-sódico, de dimensões superiores a $5 \mu \mathrm{m}$.

Na Fig. 12, estão mostrados os resultados de potencial de corrosão dos CP's curados em banho, a $38{ }^{\circ} \mathrm{C}$, e envelhecidos em solução amoniacal. Observa-se que o tempo de envelhecimento não foi significativo para demonstrar quaisquer mudanças nas propriedades analisadas. Houve uma tendência de mudança do potencial de corrosão nas últimas medidas executadas, porém, nenhum comentário conclusivo pode ser feito com relação a estas medidas, por não haver comprovação de que tais resultados permanecerão com a 

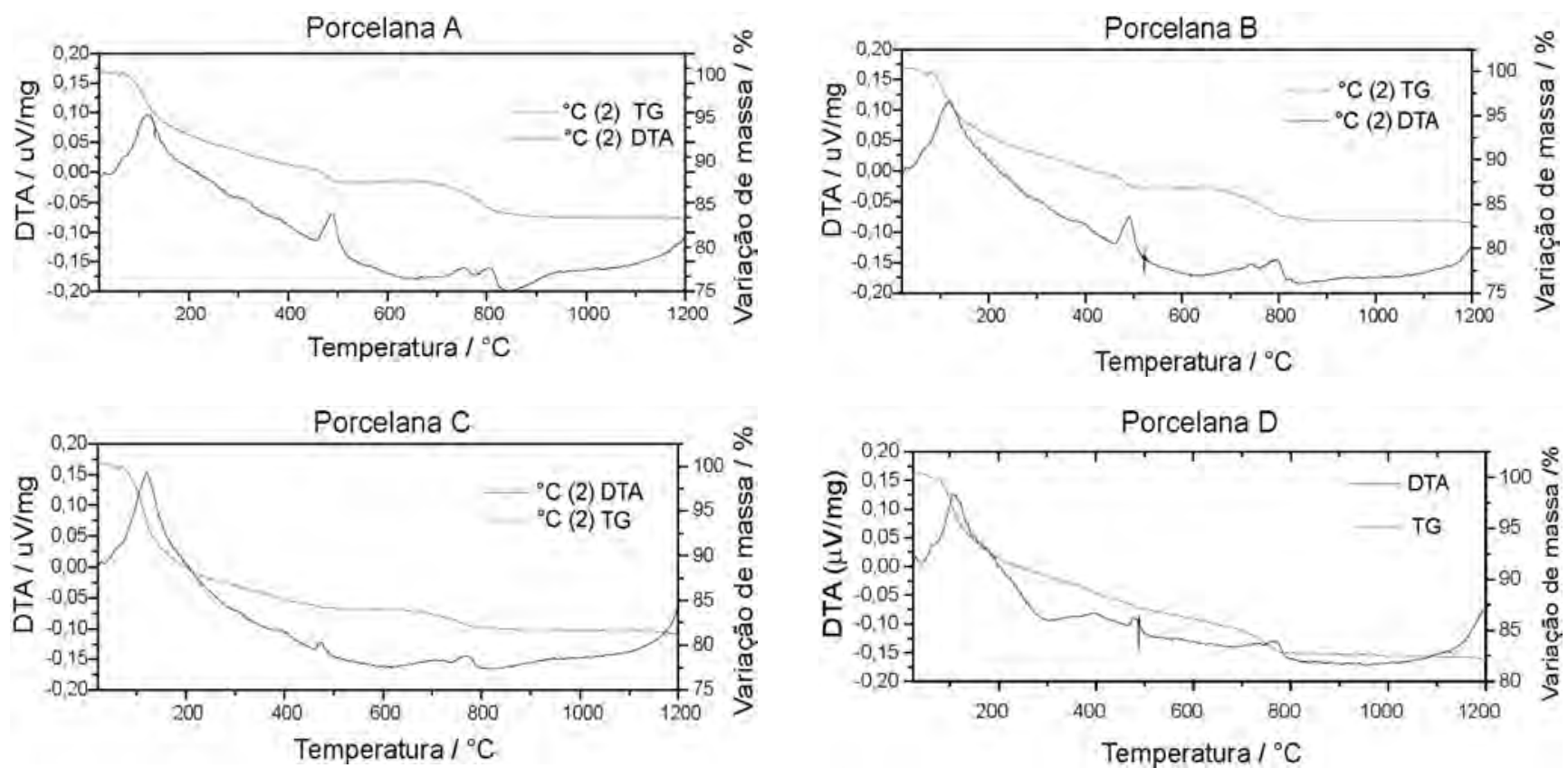

Notas: 1. Porcelana $A=7 d$; Porcelana $B=14 d$; Porcelana $C=28 d$; e Porcelana $D=91 d$ de envelhecimento, respectivamente; 2 . Sentido exotérmico na direção da abscissa (Temperatura $\left.{ }^{\circ} \mathrm{C}\right)$.

Figura 14: Curvas de DTA e TGA das amostras de concreto com cimento CPII-F 32, envelhecidas em banho de NaOH 1 N, a $80{ }^{\circ} \mathrm{C}$, durante 91 d. [Figure 14: DTA and TGA curves of the concrete samples produced with CPII-F 32 Portland cement, from 7 to $91 \mathrm{~d}$ of ageing periods in an aqueous solution of sodium hydroxide $1 \mathrm{~N}$ at $80^{\circ} \mathrm{C}$.]
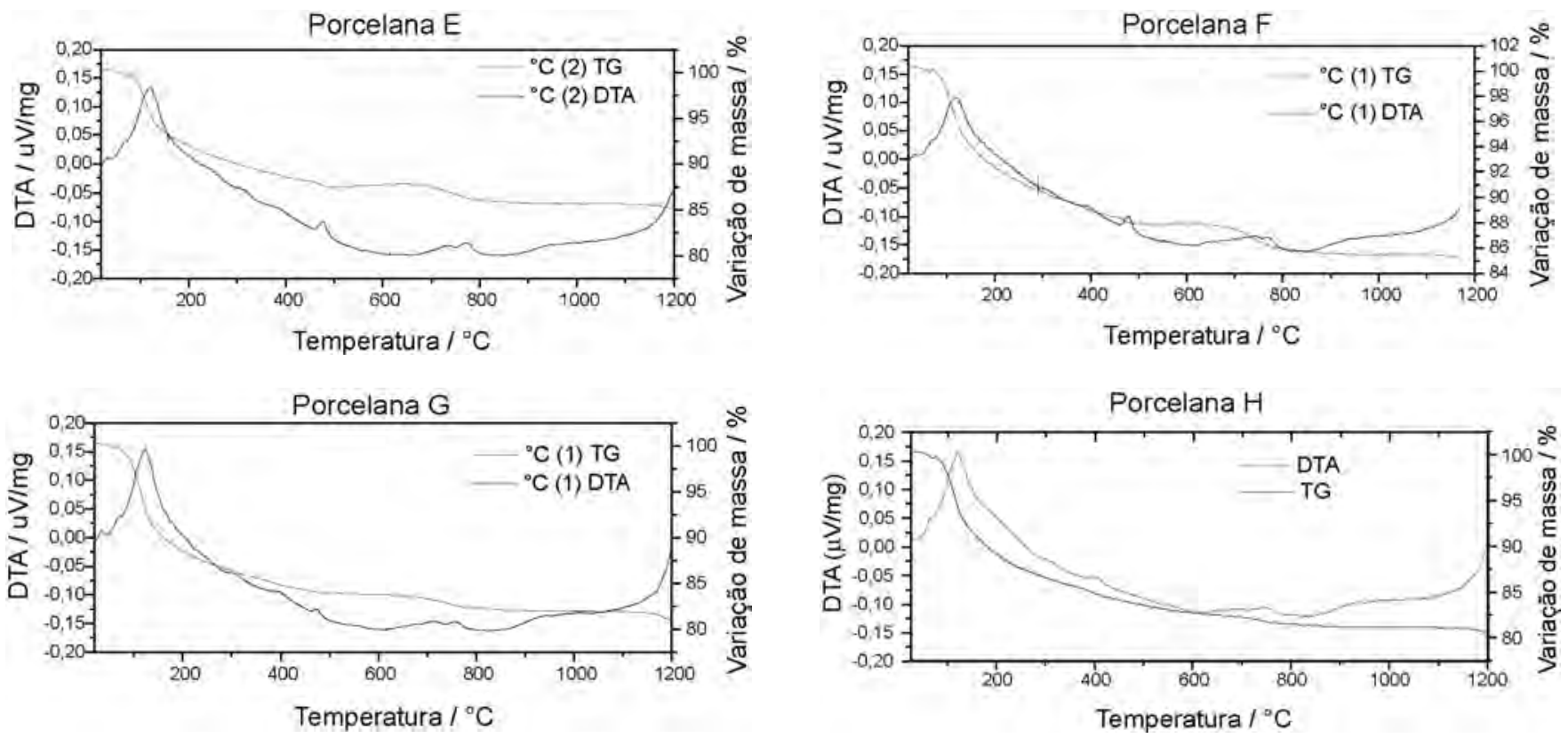

Notas: 1. Porcelana $E=7 d$; Porcelana $F=14 d$; Porcelana $G=28 d$; e Porcelana $H=91 d$ de envelhecimento, respectivamente; 2. Sentido exotérmico na direção da abscissa (Temperatura $\left.{ }^{\circ} \mathrm{C}\right)$.

Figura 15: Curvas de DTA e TGA das amostras de concreto com cimento CPV-ARI RS, envelhecidas em banho termostatizado com hidróxido de sódio $1 \mathrm{~N}$ a $80^{\circ} \mathrm{C}$.

[Figure 15: ,DTA and TGA curves of the concrete samples produced with CPV-ARI RS Portland cement, from 7 to $91 \mathrm{~d}$ of ageing periods in an aqueous solution of sodium hydroxide $1 \mathrm{~N}$ at $80^{\circ} \mathrm{C}$.] 
mesma tendência ao longo do tempo. Assim, a influência do tipo de cura nos CP's submetidos ao respectivo ensaio não pode ser verificada até o presente momento, pela técnica utilizada.

Nos CP's envelhecidos em solução de $\mathrm{NaCl}$ e $\mathrm{Na}_{2} \mathrm{SO}_{4}$, cujos gráficos resultantes podem ser visualizados na Fig. 13, percebeu-se a influência negativa do íon cloreto nas propriedades elétricas, uma vez que os potenciais medidos apresentaram-se mais elevados, indicando maior probabilidade de corrosão das armaduras. Considerandose que as medidas foram feitas sob os mesmos critérios, pôde-se notar que as composições com o cimento CPVARI RS apresentaram, na maioria das medidas efetuadas, melhor desempenho ao envelhecimento, principalmente, na de solução salina à $3,4 \%$ de $\mathrm{NaCl}$ e $2,1 \%$ de $\mathrm{Na}_{2} \mathrm{SO}_{4}$, mais visível no período estudado.

Os resultados das análises de DTA e TGA, mostrados nas Figs. 14 e 15, para as composições com cimento tipo CPII-F 32 e CPV ARI RS, respectivamente, indicaram que, com o avanço do envelhecimento e nas mesmas condições analíticas, houve redução do pico endotérmico a, aproximadamente, $490{ }^{\circ} \mathrm{C}$, relativo ao $\mathrm{CH}$ ou portlandita e que, também, houve aumento da perda de massa final, o que pode ser atribuído a uma maior absorção d'água pelo envelhecimento, ou seja, pela formação dos géis, com a respectiva perda pelo aumento da temperatura de trabalho no ensaio. Neste caso, a redução do CH presente, também, pode ser justificada pela formação dos géis e do monossulfato, pela adsorção da água livre na argamassa pelos compostos. Estas considerações encontram-se em fase de estudo para certificação, baseado em trabalhos da literatura [22] e nas próprias experiências de laboratório.

\section{CONCLUSÕES}

Do trabalho de caracterização do concreto com substituição dos agregados naturais por rejeitos de porcelana elétrica, moídos nas dimensões equivalentes dos agregados graúdos e miúdos, pode-se concluir:

1. a elaboração do traço com cimento CPV-ARI RS diminuiu a reatividade potencial aos $28 \mathrm{~d}$ para valores dentro do limite máximo especificado em norma. Porém, com a continuidade do ensaio além deste prazo, constatou-se que a expansão química resultante, apesar de ser menor do que a observada para a composição com cimento CPII-F 32, foi significativa e deve ser levada em conta quando da fabricação de estruturas que possam levar a colapso ou a travamentos mecânicos de dispositivos metálicos;

2. há uma forte dependência do ensaio da norma ASTM C1260-94 com a temperatura. Durante o período em que a temperatura do ensaio foi mantida a $(23 \pm 2)^{\circ} \mathrm{C}$, os CP's, dentro do erro de medida, praticamente não tiveram suas dimensões alteradas;

3. no período analisado e nas condições impostas, os traços de concreto testados não apresentaram redução nas respectivas propriedades mecânicas avaliadas;

4. da forma como confeccionados os traços de concreto para qualquer aplicação civil estrutural, deve ser calculado o risco de sua utilização, apesar dos traços com CPV-ARI RS resultarem melhores;

5. as medidas do potencial de corrosão da armadura foram efetivas na identificação de mecanismos de deterioração da estrutura;

6. pelas técnicas empregadas, verificou-se que há participação nas expansões químicas, em maior ou menor extensão, de todos os materiais utilizados como rejeitos: a porcelana propriamente dita, a camada superficial de vidrado e o enxofre utilizado como agente cimentante.

Finalmente, pode-se recomendar o uso de tais materiais de rejeito em estruturas que não tenham problemas conseqüentes de alguma expansão dimensional. O uso de um agente pozolânico deverá promover resultados satisfatórios quanto à reatividade potencial. Testes preliminares e de dosagens deverão ser feitos em ambos os casos.

\section{AGRADECIMENTOS}

À Companhia Paranaense de Energia (COPEL), ao Instituto de Tecnologia para o Desenvolvimento (LACTEC), à UFPR/LAMIR e à Agência Nacional de Energia Elétrica (ANEEL), pelo apoio recebido, confiança depositada, liberação de recursos financeiros e disponibilização da infra-estrutura para a realização e finalização deste projeto de pesquisa.

\section{REFERÊNCIAS}

[1] V. M. John, Tese de Livre Docência, Universidade de S. Paulo, S. Paulo (2000).

[2] Associação Brasileira de Cerâmica, http://www.abceram. org.br/asp/abc_285.asp, acesso em 13/12/2005.

[3] V. A. Paulon. Dissertação de Mestrado, Universidade de S. Paulo, S. Paulo (1981) 114.

[4] N. P. Hasparik. Dissertação de Mestrado, UFG, Goiás (1999) 255.

[5] K. L. Scrivener, J. F. Young, Mechanisms of chemical degradation of cement-based systems, $1^{\text {st }}$ Ed., London. E \& FN Spon (1997) 455.

[6] I. Biczok, Corrosión y protección del hormigón, URMO S. A. de Ediciones, Espanha (1968) 715.

[7] P. K. Mehta, P. J. M. Monteiro, Concreto - Estrutura, propriedades e materiais, S. Paulo, Ed. Pini (1997).

[8] A. M. Neville, Propriedades do concreto, PINI, $2^{\text {a }}$ Ed., S. Paulo, SP (1997) 828.

[9] S. R. Bragança, C. P. Bergmann, Cerâmica 50, 316 (2004) 291.

[10] A. L. Chinelatto, D. P. F. de Souza, Cerâmica 50, 313 (2004) 62.

[11] A. Joukoski, K. F. Portella, O. Baron, C. M. Garcia, G. 
R. Vergés, A. Sales, J. F. Paula. Cerâmica 50, 313 (2004) 12.

[12] K. F. Portella, R. Derksen, A. Joukoski, O. Baron, A. Sales. LACTEC/COPEL, ANEEL, Relatório Final 3746, Curitiba, PR (2002) 53.

[13] ASTM C1260, Standard test method for potential alkali reactivity of aggregates (mortar-bar method), Philadelphia, EUA (1994).

[14] ASTM C 227, Standard test method for potential alkali reactivity of cement-aggregate combinations (mortar-bar method), Philadelphia, EUA (1990).

[15] ABNT, Concreto - Ensaio de compressão de corposde-prova cilíndricos de concreto - Método de ensaio, NBR 5739, Rio de Janeiro (1994).

[16] ABNT, Determinação do módulo de deformação estática e diagrama tensão-deformação, NBR 8522, Rio de Janeiro (1984).
[17] ABNT, Argamassa e concreto - Determinação da resistência à tração por compressão diametral de corpos-deprova cilíndricos, NBR 7222, Rio de Janeiro (1994).

[18] ABNT, Concreto - Determinação da resistência à tração na flexão em corpos-de-prova prismáticos, NBR 12142, Rio de Janeiro (1991).

[19] ABNT, Cimento Portland composto - Especificação, NBR 11578, Rio de Janeiro (1991).

[20] ABNT, Cimentos Portland resistentes a sulfatos, NBR 5737, Rio de Janeiro (1992).

[21] ABNT, Postes de concreto armado para redes de distribuição de energia elétrica - Especificação, NBR 8451, Rio de Janeiro (1985).

[22] N. P. Hasparyk, P. J. M. Monteiro, H. Carasek, Anais $43^{\circ}$ IBRACON, Foz do Iguaçu, PR (2001) II-025 (cd rom).

(Rec. 13/01/2006, Ac. 20/04/2006) 